\title{
Digital Cadastral Maps in Land Information Systems
}

\author{
by PIOTR CICHOCINSKI
}

\begin{abstract}
This paper presents the problem of cadastral maps. The hitherto existing cadastre, consisting of paper maps and land registers, is now becoming insufficient. Its shortcomings force developments leading to its improvement. One of the ways is the creation of a Land Information System. A digital cadastral map is the main component of this system.

The structure and information content of the map is presented, its differences from analogue maps are shown, and the process of map creation is described.

A digital cadastral map can be the basis for additional thematic layers, successively converting it into a complex system for management of administrative units. Some examples of such layers and their usage are presented here.
\end{abstract}

\section{THE PAST}

Traditionally the cadastre was created for fiscal purposes. This was already the case in Antiquity (Assyria, Egypt, Rome). In the course of time the cadastre started to be used also for other purposes. It came to be the basis for establishing land registers and at the same time was used for the protection of property.

The first cadastre in Poland was established in the nineteenth century, whilst the contemporary Polish cadastre was created in the 1960s. Its base document is the land register. The land register is the list of owners and all the parcels they possess (fig. 1). The cadastral map only serves in an auxiliary role showing spatial structure of objects (fig. 2). Spatial structure consists of parcel boundaries, ground use boundaries and class boundaries. Each object is described by an identifier. 


\section{Digital Cadastral Maps in Land Information Systems}

The data resulting from the classical model of land cadastre are now becoming insufficient. In the course of economic development the demand for more varied information items becomes increasingly pressing. Data stored in traditional cadastral systems fail to meet requirements connected with supervision, management, decision-making, forecasting and development planning.

The most significant problems are:

- low precision of geometric data;

- quality and speed of data access;

- divergence between the map and the register;

- lack of supervisory tools.

Another kind of problem is the possibility for performing analyses and reports. Using the traditional, analogue register its owner is unable to state in an easy way a basic parameter such as the number of described parcels.

\section{EvOLUTION}

These shortcomings have forced the improvement and upgrading of the cadastre, which can be observed in many countries. These processes evoke both model changes and alterations of the systems' unitary features. They tend to proceed in two directions:

- the expansion of the classical cadastre model to cover new issues;

- the construction of land information systems (LIS) and, more generally, geographic information systems (GIS), to a certain extent based upon the cadastre, which has already been running.

The latter solution was chosen in Poland. Since 1991 the process of conversion of the existing cadastre from the analogue to digital form and creation of the basis of countrywide LIS is being realized.

\section{The Present}

The modern cadastre can be described as a full and comprehensive inventory of land ownership structure countrywide, incorporating the official survey of land and buildings (often including apartments) designed primarily to meet fiscal needs. In this system the boundaries of real estate items and their constituent sites are established following the latest legally valid ownership 
documentation backed up with geodesic and cartographic documentation of the boundary. A modern cadastre, entered completely into a computer system, has to include real estate data to determine its:

- cadastral identifier and links to other computer systems;

- location;

- boundary route;

- land use;

- components distinguished with respect to a different function or land use;

- technical fittings (mains connections);

- land purpose assigned in the local spatial development plan;

- distinct attributes of a particular real estate, especially its surface and value.

It should answer two basic questions:

What is at a particular location? A location can be described in many ways using, for example, a place name, an address, or a geodesic reference such as co-ordinates.

Where are certain conditions to be found? The second question is the converse of the first and requires spatial analysis to be answered. Instead of identifying what exists at a given location, someone may want to find a location where certain conditions are satisfied (e.g., all parcels owned by a particular person).

A cadastre determined in this way is a basis for any official activity related to real estate. Moreover, it may serve the purpose of validating charges and other public obligations, such as legal processing, the real estate market, land economy, and the completion of any spatial development plan. A modern cadastral system can be referred to as a multitask cadastre. Its fundamental importance for the future is the possibility of linkage with other subsystems, leading to their integration within the frame of LIS/GIS structures.

The construction of the cadastral system begins with implementing computer systems at the local level, that is in municipalities and communes. In the first stage they will function autonomously. In the second stage local cadastral systems should be linked at the regional level, with elements of management decentralization corresponding to the structure agreed upon. Subsequently the operating range of the cadastral system should be expanded gradually and the system should be linked to other subsystems (spatial development plans, building registers, technical networks, population census, etc.). In the next stage, activities of particular local and regional subsystems should be coordinated in order to create a countrywide cadastral system. 
Digital Cadastral Maps in Land Information Systems

\section{Digital Cadastral Map}

The digital cadastral map is the fundamental component of any cadastral system. However, the digital cadastral map is not a map in the traditional sense.

The map is not stored in any conventional sense; nor is it an image or view of a geographic area. Instead, the data are stored, from which it is possible to draw a desired view to suit a particular purpose. Although it can be displayed and printed at different scales, in different projections, and with different colours, it is in fact an analytical tool. Its major advantage is that it displays the spatial relationships between features depicted on it. There are two basic types of map information:

- spatial information, which describes the location and shape of geographic features and their spatial relationships to other features;

- descriptive information about the features.

Spatial data are obtained by a certain representation of real-world objects with the application of rules determined beforehand, defining which objects and attributes are to be selected, which definitions to be used, and how they should be stored and visualized. The basic characteristics, which distinguish geographic features from other features contained in the database (although a geographical object may also occur in raster or vector form), are their geometric characteristics.

Geographic features too small to be depicted as lines and areas are represented by points, features too narrow to depict as areas are represented by lines, and homogeneous geographic features are represented by areas. Such points, lines and areas are represented as a list of coordinates instead of as a picture or a graph.

Map features are logically organized into sets of layers or themes of information. A basic cadastral map is organized into layers such as parcels, land use, land classification, and buildings (fig. 3).

Relationships are very important, as they help the user to understand situations and to make decisions. They are implicit on map sheets; they depend upon a map reader who interprets them. For example, one can determine:

- which geographic features connect to others (e.g., $5^{\text {th }}$ Avenue connects with Main Street);

- which geographic features are adjacent (contiguous) to others (e.g., two adjacent parcels); 
- which geographic features are contained in an area (e.g., a building is located on a parcel);

- which geographic features intersect (e.g., the railway crosses the road).

In digital maps spatial relationships are depicted using topology. Topology is a mathematical procedure for explicitly defining spatial relationships. Topology expresses different types of spatial relationships as lists of features (e.g., as area is defined by the lines comprising its border).

Spatial data are linked with non-geographic (descriptive) information about a particular feature on a map. The information is stored as attributes of the geographically represented feature. Those attributes may have the form of labels (tags) attached to the graphic elements and are stored in vector files or as tabular data, on which certain analyses can be conducted. The first solution is used mainly to provide simple information on particular objects like the object's name, date of placement, etc. The latter case requires an external database, the records of which are linked with corresponding graphical map objects (fig. 4).

The values of those attributes are:

- quantitative, measured and expressed with units of length, area, time etc.; or

- qualitative, when each attribute may assume only one value out of a set of values, determined before, such as names, addresses, colours etc.

The power of the system lies in its ability to link the two types of data (spatial and descriptive) and maintain the spatial relationships between the map features. There are three noteworthy characteristics of this connection:

- There is one-to-one relationship between features on the map and the records in the feature attribute table;

- the link between the feature and its record is maintained through a unique numerical identifier assigned to each feature;

- the unique identifier is physically stored in two places: in the files that contain the coordinates and with the corresponding record in the feature attribute table.

The concept described above applies to more than just keeping track of features and their attributes. It is possible to connect any two tables if they share a common attribute. A common item is used to establish connections between corresponding records in two tables. Each record in one table is connected to a record in another table that shares the same value for a common item. 


\section{Digital Cadastral Maps in Land Information Systems}

Integrating graphic and tabular data opens the way for powerful new ways of looking at and analyzing data. It is possible to access information in the tabular database through the map, or to create maps based on the information in the tabular database. For example, the area that represents a parcel on a map does not tell much about the parcel except its location and shape. To find out the parcel's owner, one could use the computer's screen cursor to point at a parcel on the map and display a list of all relevant descriptive information (fig. 5). Conversely, using the information stored in the database, it is possible to create a display symbolizing the parcels belonging to one particular owner.

Stored feature attributes can be used to compute new information about map features; for example, to calculate the length of a particular border between two parcels or to determine the area of a particular parcel.

Several methods of creating digital maps are possible, depending on the state and validity of available source materials and the accuracy required:

- The existing analogue maps are scanned and raster images obtained this way are refined and calibrated with use of points with known coordinates. Such a picture, when magnified in a monitor screen enables the operator to construct its precise vector representation.

- The survey results are processed by means of geodesic calculating programmes into a form of a specification of measured points (parcel boundary bend points, building corners etc.) recorded in digital format. These points are then automatically generated as the vector elements of a graphic file and can subsequently be connected by the operator to create proper objects of a digital map.

\section{THE FUTURE - GEOGRAPHIC INFORMATION SYSTEM}

Cadastral data will soon become the part of the geographic information system. Entering the data into the geographic information system first of all gives the possibility to create thematic maps.

Such a map (fig 6) shows certain aspects of presented objects in a very clear way. It can be queried to show the information about the particular object depicted on it (fig. 7).

Geographic information system usually contains more thematic layers than a simple cadastral database. One of them can be digital elevation model (fig. 8), which represents the shape of the earth's surface. 
Such a model gives more analytical possibilities than contours derived from the paper maps. It can be used to do the following tasks:

- $\quad$ aspect and slope calculations;

- visibility computations;

- insolation analysis.

Derivative data resulting from these processes can be used to enrich the cadastral database. For example, it can now contain the data about soil erosion risk and insolation, which can help to assess the parcel value better. In addition, two-dimensional data can be overlaid on the model, making presentations very attractive.

\section{CONCLUSION}

Until only a few years ago the map was perceived as a static, plain view of preselected areas, available at fixed scales and, due to the development of the landscae, often out of date. Now, it is evolving into a dynamic, continually updated network of interrelated databases with volumes of geographically referenced information linked to a comprehensive digital cadastral database.

Piotr Cichocinski

Department of Land Information Systems

University of Mining and Metallurgy

al. Mickiewicza 30

30-059 Kraków, Poland

cichocin@uci.agh.edu.pl

$<$ http://www.galaxy.uci.agh.edu.pl/ cichocin> 
Digital Cadastral Maps in Land Information Systems

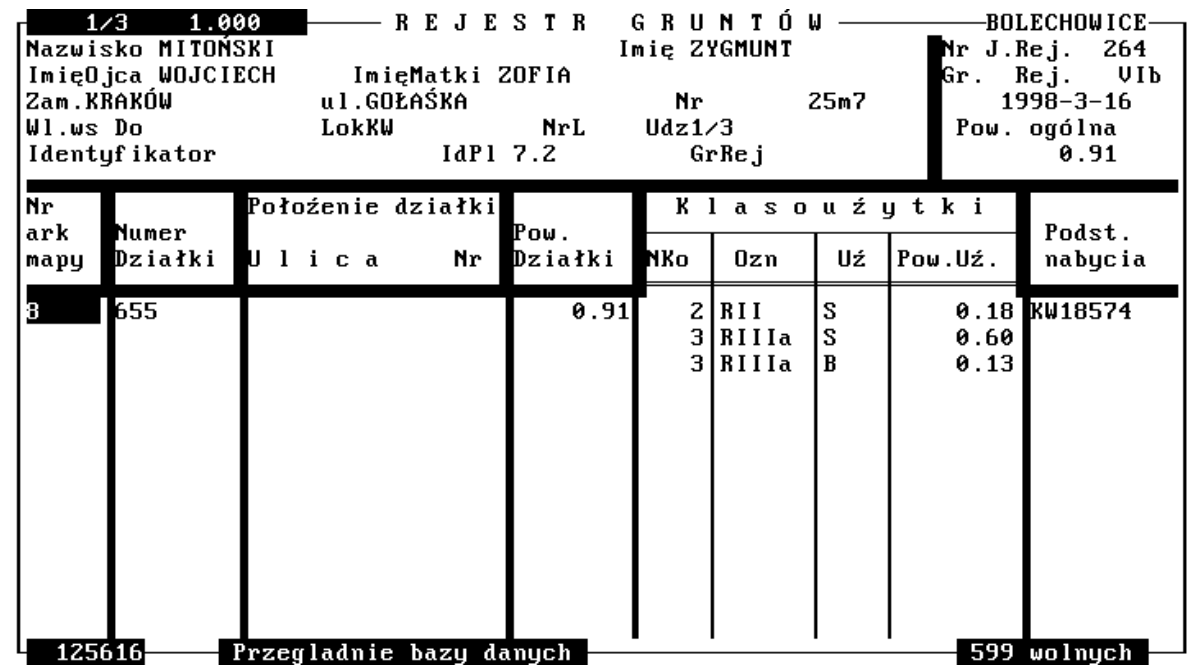

Fig. 1. Land register.

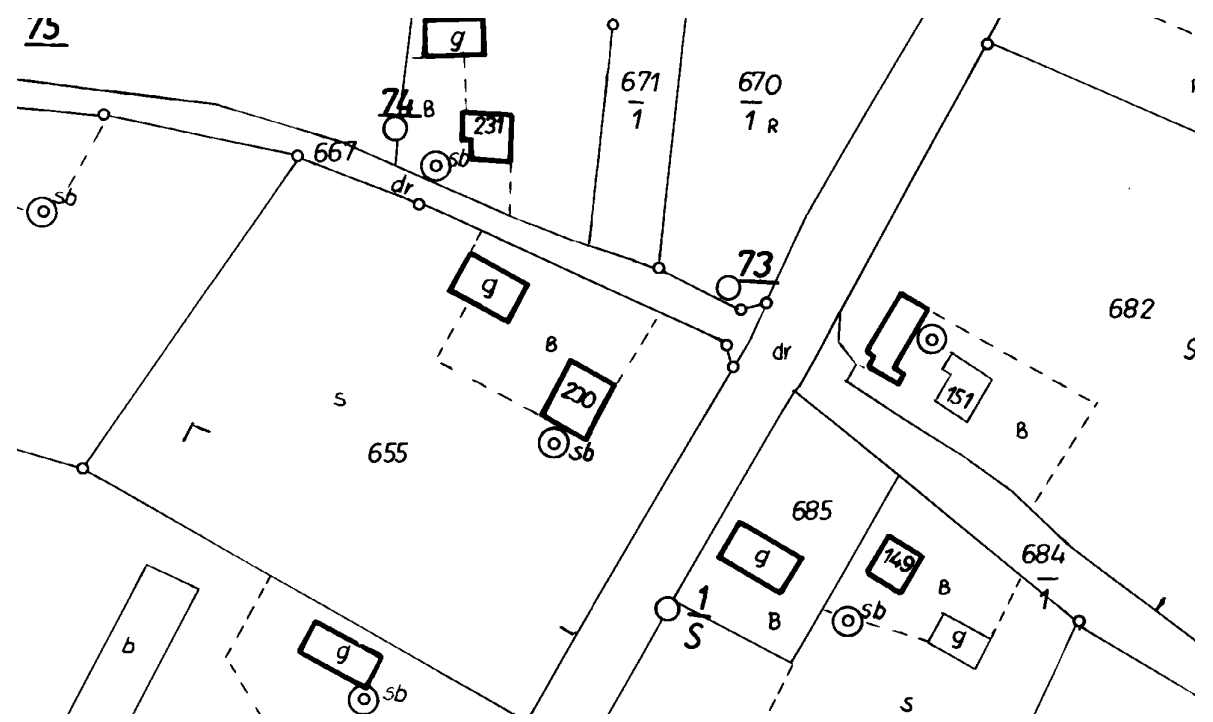

Fig. 2. Cadastral map. 
PIOTR Cichocinski

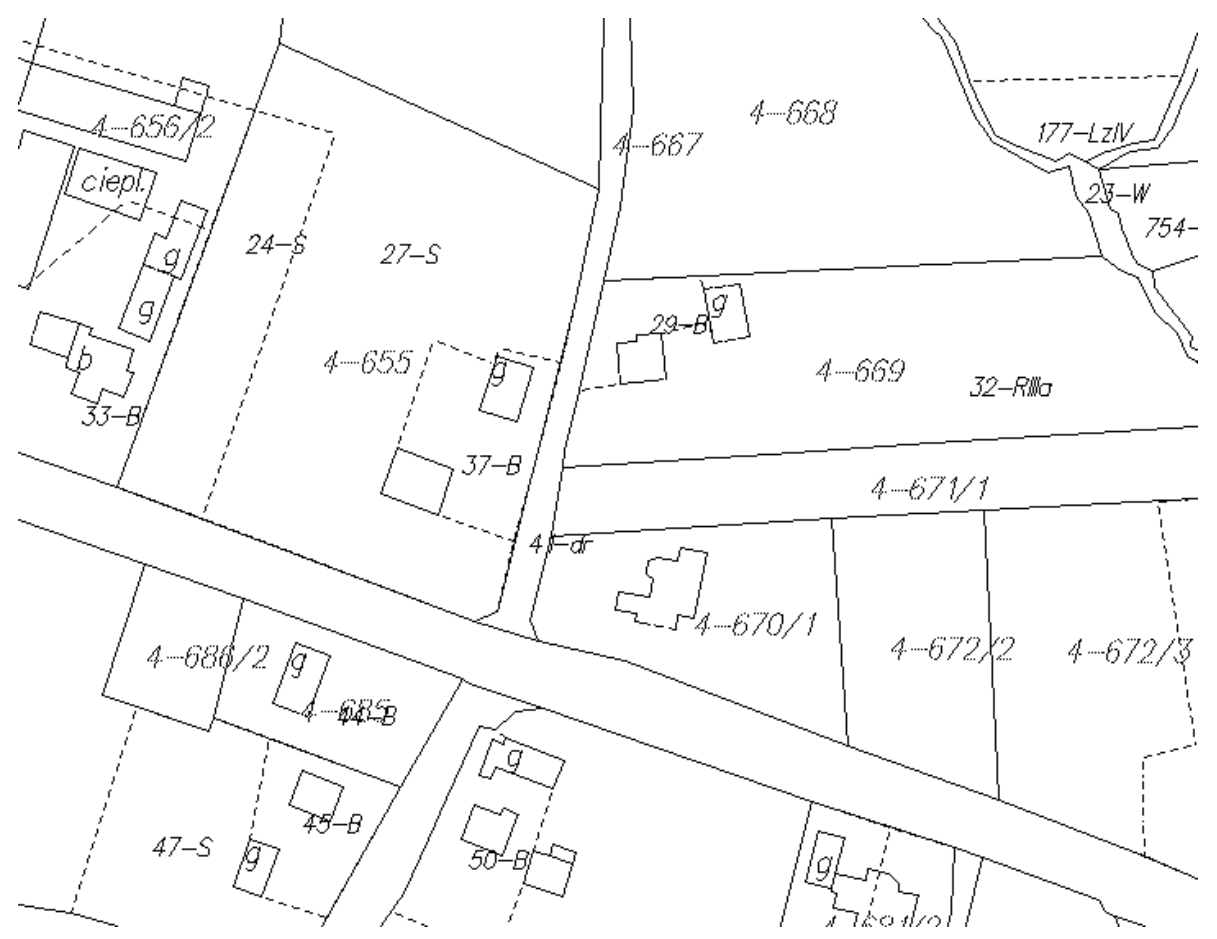

Fig. 3. Digital cadastral map.

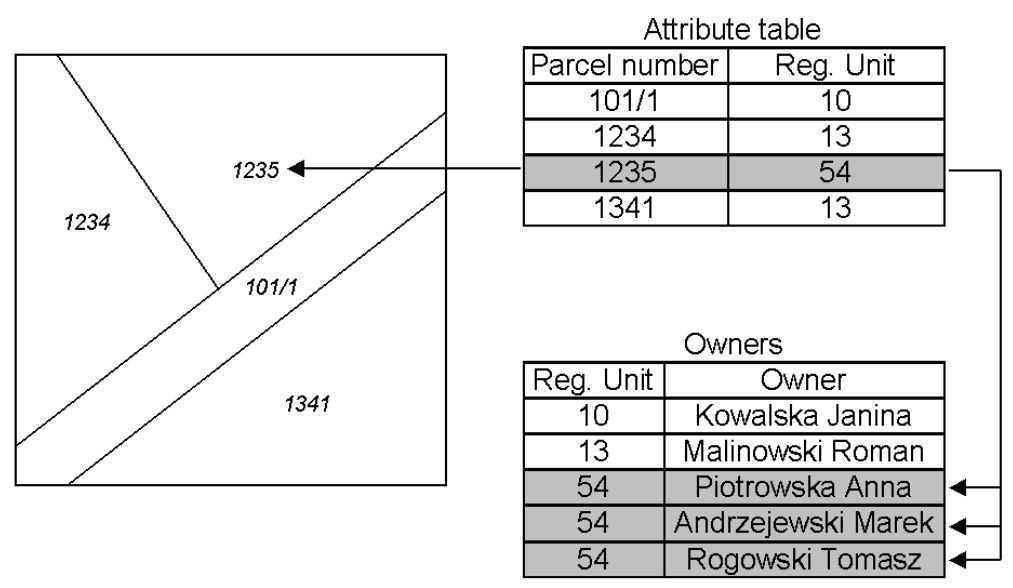

Fig. 4. Graphic and tabular data integration. 
Digital Cadastral Maps in Land Information Systems

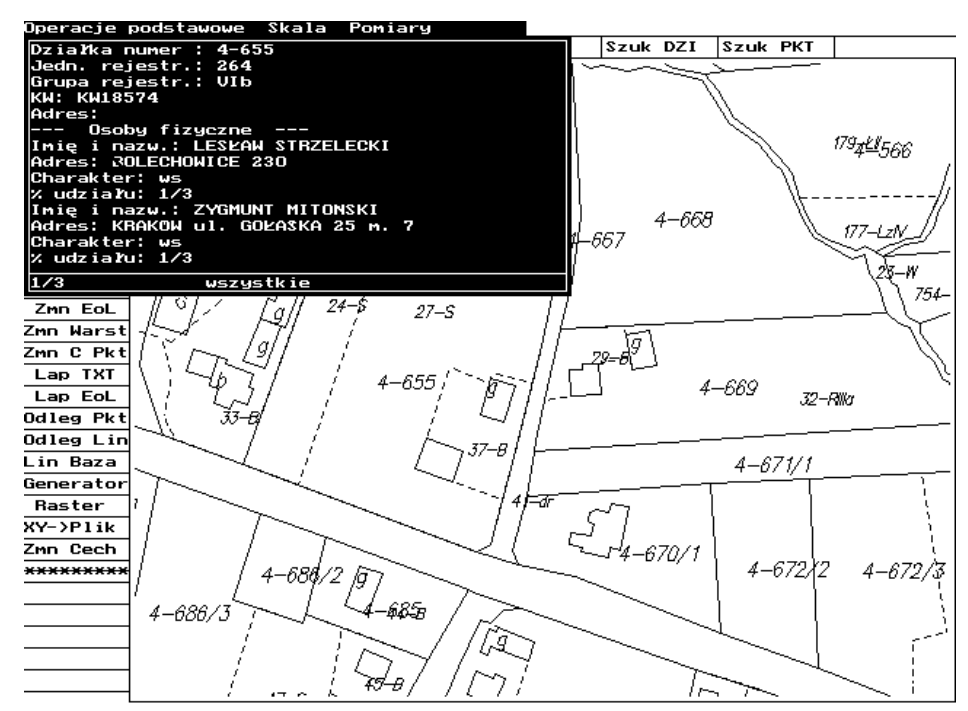

Fig. 5. List of descriptive information about parcel [4-655]

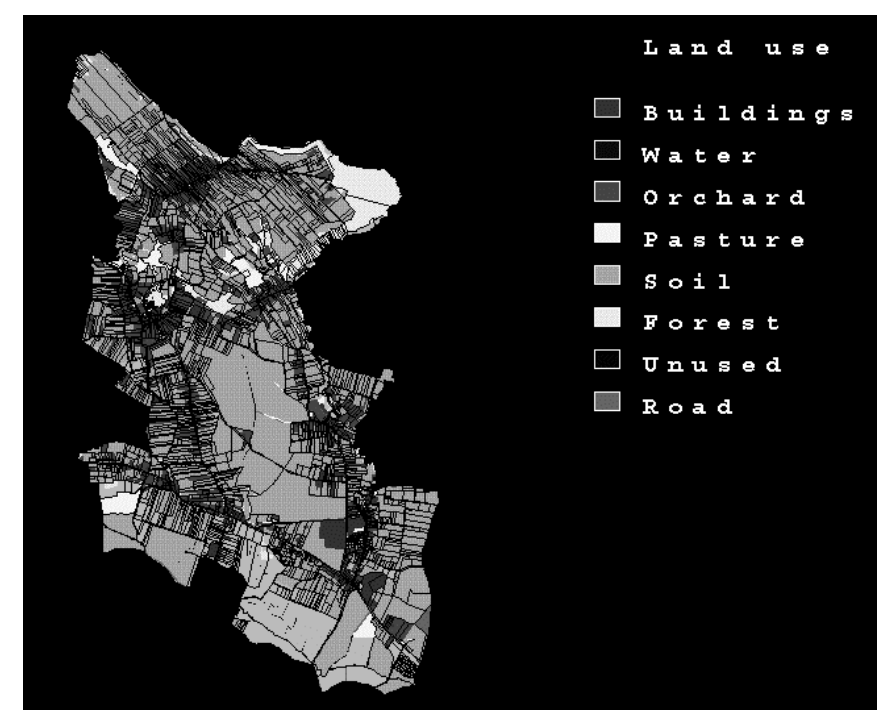

Fig. 6. Thematic map. 


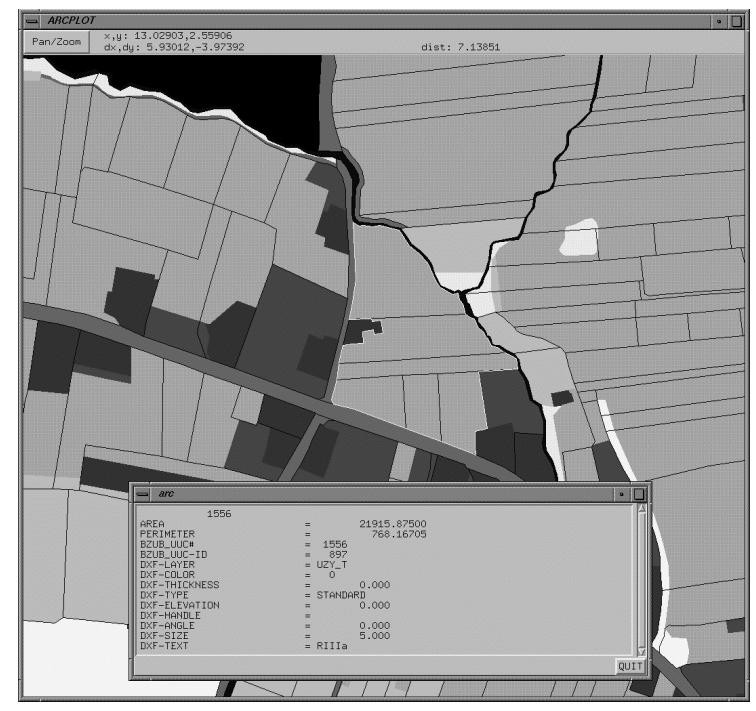

Fig. 7. Database query.

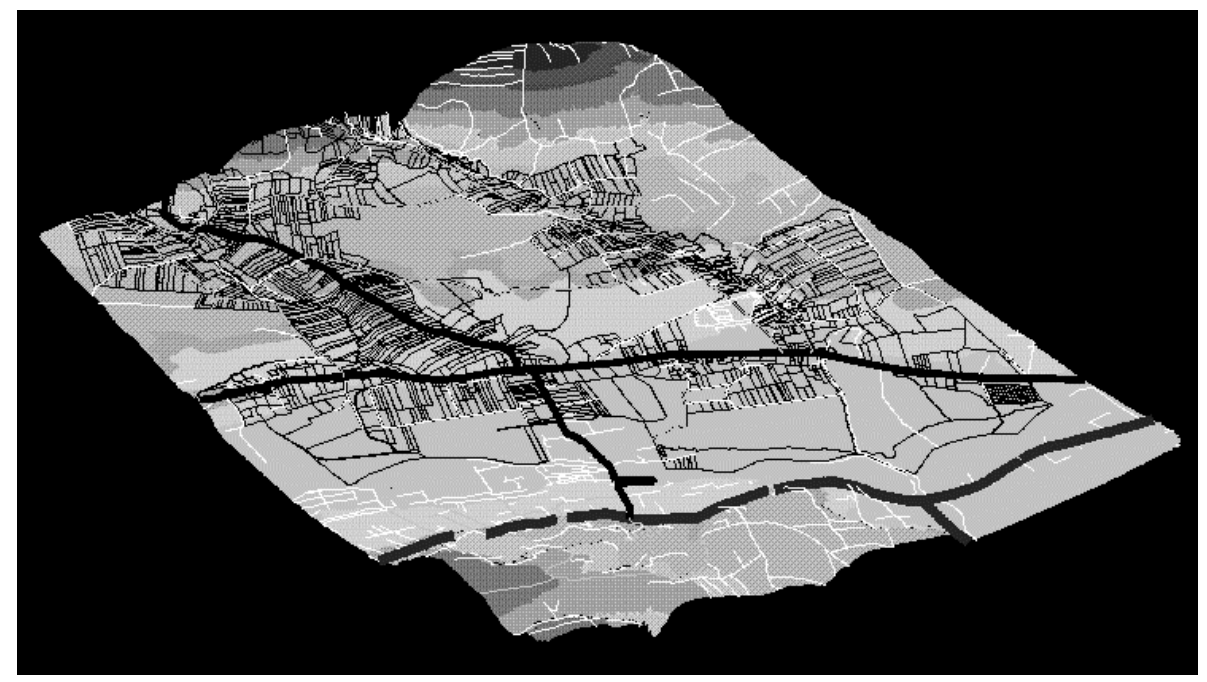

Fig. 8. Digital elevation model. 